\author{
Lecturer Cristina STATE, PhD \\ E-mail: cristina.state@man.ase.ro \\ The Bucharest University of Economic Studies \\ Professor Dan POPESCU, PhD *Corresponding author \\ E-mail:dan.popescu@man.ase.ro \\ The Bucharest University of Economic Studies \\ Professor Minodora URSĂCESCU, PhD \\ E-mail: minoursa@man.ase.ro \\ The Bucharest University of Economic Studies
}

\title{
EMPIRICAL RESEARCH REGARDING THE HEAVY WORK INVESTMENT AND WORKAHOLISM OF UNIVERSITY STUDENTS AND GRADUATES
}

\begin{abstract}
Each and every person's success is strictly dependent on the extent to which investments are made to train them in the spirit work and to foster a favourable attitude to work. We dedicate most of our life to work and what matters most is not our workplace, but the skills and expertise gained as a result of our activity. The educational system encourages us to work as much as possible. Although, overall, work is positive for each of us, when it becomes excessively important it generates some of the most unfavourable effects, becoming a sine qua non condition of our existence. The main objective of our research was to analyse the significance and effects of heavy work investment (HWI) at individual and social level, as well to quantify the impact of workaholism (W) and work addiction (WA) on human existence. The quantification refers to the connection between the phenomenon of the ever higher dedication to work of the young generation and the results of their work. The data used to this purpose were obtained from 1063 people by means of a questionnaire. The quantitative approach was based on rigorous statistical and mathematical methods (analysis of variance ANOVA, Factor Analysis and Principal Component Analysis), and the data were processed with the help of SPSS. The results obtained highlighted the fact that encouraging involvement in the work process up to the point of developing an addiction can have extremely harmful effects, generating social isolation, psychological alienation and even physical disappearance, as a direct consequence of what the Japanese call "karoshi" (death by overwork).
\end{abstract}

Key words: workaholic; work-addiction; work excess; work engagement; employee well-being.

JEL Classification: C12; C44; C83; I25; J70; M54

DOI: $10.24818 / 18423264 / 55.1 .21 .10$ 
Cristina State, Dan Popescu, Minodora Ursăcescu

\section{Introduction}

It is a proven fact that our success depends on how much we invest in work, but also on the way in which society as a whole influences the work education and mentality (Joubert, 2020). In time, we have become more and more addicted to work and forgot that by definition, irrespective of its nature, addiction is harmful and generates moralizing effects (Earp et al, 2019). By becoming increasingly addicted to work, we manage to achieve the counter performance of believing that our superiors appreciate us to the extent to which we are investing in work. But are we talking about an investment or about an ever more exacerbated way of understanding ourselves and relating our existence to work?

Especially nowadays, as far as work is concerned, the two way dilemma "working to live or living to work?" is extremely fine, exceptionally complex, but also intensely debated (Schram, 2019). We are being urged to do everything with passion and complete devotion (Park, Martina and Smolka, 2019). The idea is instilled into us that when we like what we do and we put passion into it, we no longer feel that we are making an effort or that we are working hard (Moss, 2019). Even Confucius was advising us: "Choose a job you love and you will never have to work again" (Ford and Conners, 2010). But is this true? And if it is, up to what point? Whenever our own effort becomes less noticeable to us, the ones near us feel it much more (Babic et al, 2019). Under such circumstances, do we know when to stop working and focus on other aspects of our life or do we tend to take refuge into work, sticking to our conviction that that is the comfort zone we can control? How do we find our balance when we work out of passion and we dedicate more and more to our professional activity, neglecting other important aspects of our life? Is it beneficial to work as much as possible, for as long as we can and if so, for whom and what for? Can there appear negative effects on the organisation we are part of, caused by our desire to work as much and as intensely as possible? What kind of effects can there be? Finally, is $H W I$ leading to $W$ a good or a bad phenomenon? These are just some of the questions which have guided our research and to which we will try to offer some possible answers.

\section{Literature review}

The sustainability of our endeavours to achieve success depends greatly on the extent to which we invest in work. However, the importance of work takes precedence over exclusively economic reasons. Consequently, it is obvious that dedicating most of our time to work is not the most important thing, because what matters most are the expertise and skills gained by performing our activity (Peart, 2019). More and more we are oriented and intensively educated to be perfectionists (Smith, et al., 2019) and to work as much as possible in an environment dominated by uncertainty so that we should be as prepared as one can be for the "jobs of the future" (Kirschner and Stoyanov, 2020). Overall, although work has a positive value to each of us, it may generate very dangerous effects (Listau, Christensen and Innstrand, 2017).

Our various behavioural types resulting from an increase in the time dedicated to work have started to be studied as early as the 70 s under the name of $W$, defined as 


\section{Empirical Research Regarding the Heavy Work Investment and Workaholism of University Students and Graduates}

the compulsion or uncontrollable desire to work incessantly (Oates, 1971). Both the colloquial and academic usage of the word (Schmall, 2019) indicate that not only does $W$ deeply affect the interpersonal relationships among colleagues but it also represents the main form of manifestation of the HWI phenomenon. HWI, a concept which has been recently introduced in the specialised literature by Harpaz and Snir (2014), refers to dedicating a high amount of time and intense physical and psychological efforts to work. As work is becoming more and more important (Subramanian, 2018), we are growing increasingly dependent on it (Wojdylo, 2015), transforming it into a real myth (Griffits, Demetrovics and Atroszko, 2018). Moreover, we even manage the "performance" of considering that the appreciation we receive from our superiors (Van Beek et al, 2014) is related to our HWI.

But is it an investment or an ever more brutal way of understanding and relating our existence to work? Although $W$ has been studied and debated for the last five decades, the digital era has added a new dimension to the WA concept. Thus, the new technologies provided by the IT\&C industry and more recently, unfortunately, by the coronavirus pandemic crisis, are offering people the opportunity to work from anywhere, anytime and, in some cases, as much as they can. Even if due to work flexibility people have more opportunities, is it good that we should work longer and more intensely? The contradicting results obtained by the research carried out so far have prompted us to set as our main objective identifying a point of view about how $H W I, W$ and $W A$ can be really useful processes or not at individual and social level (Huyghebaert et al, 2018).

Within this context, our research intends to analyse a series of positive and negative influences of the $W-H W I-W A$ trinome on the training and especially on the expertise of young university graduates. "Employability skills" are essential, especially as young people are encouraged to start working while they are at university, on the one hand in order to gain new skills and experience, thus becoming more desirable for the employers, and on the other hand in order to provide for their day to day financial needs (Berman, 2018). Encouraging undergraduates to find a workplace may, however, have both favourable and unfavourable effects. The favourable ones appear in case their experience comes from participating in internships organised by the universities or from cooperating with various entrepreneurs. Unfavourable effects can occur because, undoubtedly, one cannot achieve perfection while doing two things at the same time: university studies and a job, which means that becoming employed can have a negative impact on one's academic results (Baert et al, 2017). Other aspects to be considered are the authorities' policy regarding the alternation between university studies - employment (Scholz-Fenech and Raykov, 2018), the type of work performed by undergraduates and its influence on the success in the world of work (SanchezGelabert, Figueroa and Elias, 2017).

Therefore, our research aims to analyse to what extent and how work education ever since the faculty years, leading to higher chances of obtaining interesting and well-paid jobs, are useful phenomena or on the contrary unfavourable ones, generating frustration in the professional and personal life alike. Last, but not least,

DOI: $10.24818 / 18423264 / 55.1 .21 .10$ 
we wanted to analyse and to debate to what extent the famous binome of perfectionism and narcissism generates and feeds $W, H W I$ and WA.

\section{Objectives, hypotheses and research methodology}

The objective of our research consists in using Data-Mining technologies (Analysis of variance - ANOVA, Factor Analysis and Principal Components Analysis) in order to identify the factors which account for the people's propensity to make $H W I$, up to the point of becoming workaholic, as well as to highlight and quantify the causes and effects of this phenomenon. Our main hypothesis $(M H)$ was that the HWI of university students and graduates leads to $W$ which, in its turn, has a negative impact on the quality of their personal and professional life. Four secondary hypotheses $(\mathrm{SH})$ were also formulated, as follows:

$\mathrm{SHI} \rightarrow$ the inclination toward HWI is cultivated ever since childhood, through the education received within the family;

$\mathrm{SH} 2 \rightarrow$ the individuals' HWI is also the result of the influences exerted by the environment (such as the fear of feeling embarrassed in front of others);

$\mathrm{SH} 3 \rightarrow$ the individuals' HWI has deeply negative effects on their psychological health; SH $4 \rightarrow$ the individuals' HWI is also stimulated by their need, as educated people, that their place, role and social usefulness should be acknowledged by the others.

In order to reach our research objectives, we opted for a quantitative approach, based on the use of statistical and mathematical methods, using data obtained from a survey carried out with the help of a questionnaire which was distributed online at <https:// isondaje.ro/sondaj/748451261/>. The sample used in the quantitative analysis included university students and young graduates from the four biggest university centres in Romania (Bucharest, Cluj-Napoca, Iaşi and Timişoara). In order to obtain the sample we used quota sampling, which is a non-probability sampling method, combined with the snowball method (Șandor, 2012), which we considered to be more adequate for the analysis. Unfortunately, the sampling procedure used did not allow us to assess the sample representativeness.

As a multidimensional research method we opted for the analysis of variance (ANOVA), the most frequently used method in empirical research (Ostertagova and Ostertag, 2013), while the processing of the data obtained from the respondents was made with the SPSS software tool. Given a statistical population structured into $\boldsymbol{n}$ groups or sub-populations whose elements have a single characteristic, in ANOVA we assume that there are $\boldsymbol{n}$ normal and independent aleatory variables (probability distributions) $X_{1}, X_{2}, \ldots, X_{n}$, with an unknown mean $\mu_{1}, \mu_{2}, \ldots, \mu_{n}$ and unknown, equal variances $\sigma_{i}^{2}$, i.e. $\sigma_{i}^{2}=\sigma^{2}$. This implies considering a single factor of influence with $\boldsymbol{n}$ levels, each level determining a single distribution of values for the independent variable. Verifying whether and to what extent the influence of the factor on this variable is significant or not is equivalent to checking if the $\boldsymbol{n}$ distributions have the same mean or not, or to check a null hypothesis of the form:

$$
\mathrm{H}_{0}: \mu_{1}=\mu_{2}=\ldots=\mu_{\mathrm{n}}=\mu,
$$

where $\mu$ is an unspecified value.

The alternative $\mathrm{H}_{1}$ hypothesis corresponding to the $\mathrm{H}_{0}$ null hypothesis includes all the 


\section{Empirical Research Regarding the Heavy Work Investment and Workaholism of University Students and Graduates}

situations when at least two mean values $\mu_{\mathrm{i}}$ and $\mu_{\mathrm{j}}$ are different from each other. In ANOVA, the individual behaviour of each aleatory variable $X_{i t}(i=1,2, \ldots, n ; t=$ $1,2, \ldots, \mu_{\mathrm{i}}$ ) is seen as being given by a multitude of accidental variations surrounding the average behaviour of this variable, represented by its expected value, these variations being synthesized by means of the stochastic disturbances marked as $\varepsilon_{\mathrm{i}, \mathrm{t}}$. This assumption is equivalent to the supposition that the individual manifestations of the behaviour of each aleatory variable $\mathrm{X}_{\mathrm{it}}$ are described by the model:

$$
\mathrm{X}_{\mathrm{it}}=\mu_{\mathrm{i}}+\varepsilon_{\mathrm{it}}, \mathrm{i}=1,2, \ldots, \mathrm{n} ; \mathrm{t}=1,2, \ldots, \tau \mathrm{i}
$$

Taking into consideration this information is equivalent to a single factor experiment, where the number of levels of the factor equals $n$ and the number of observations per cell is variable and equals $\pi_{\mathrm{i}_{\mathrm{i}}}$.

We will mark as $\overline{\mathrm{X}}_{1}, \overline{\mathrm{X}}_{2, \ldots}, \overline{\mathrm{X}}_{\mathrm{n}}$ şi $\overline{\mathrm{X}}_{\mathrm{G}}$ the estimators for each mean of the $n$ distributions taken together, defined by the equations:

$$
\overline{\mathrm{X}}_{\mathrm{i}}=\frac{1}{\tau_{\mathrm{i}}} \sum_{\mathrm{t}=1}^{\tau_{\mathrm{i}}} \mathrm{X}_{\mathrm{it}} ; \quad \overline{\mathrm{X}}_{\mathrm{G}}=\frac{1}{\mathrm{~T}} \sum_{\mathrm{i}=1}^{\mathrm{n}} \sum_{\mathrm{t}=1}^{\tau_{\mathrm{i}}} \mathrm{X}_{\mathrm{it}},
$$

where: $\mathrm{T}=\tau_{1}+\tau_{2}+\ldots+\tau_{\mathrm{n}}$ and it represents the total number of the observations of the $\boldsymbol{n}$ samples.

The estimator of the sum total of the squared deviations of the T observations around the general average can be written in the following form:

$$
\mathrm{SS}_{\mathrm{T}}=\sum_{\mathrm{i}=1}^{\mathrm{n}} \sum_{\mathrm{t}=1}^{\tau_{\mathrm{i}}}\left(\mathrm{X}_{\mathrm{it}}-\overline{\mathrm{X}}_{\mathrm{G}}\right)^{2}=\sum_{\mathrm{i}=1}^{\mathrm{n}} \sum_{\mathrm{t}=1}^{\tau_{\mathrm{i}}}\left(\mathrm{X}_{\mathrm{it}}-\overline{\mathrm{X}}_{\mathrm{i}}\right)^{2}+\sum_{\mathrm{i}=1}^{\mathrm{n}} \sum_{\mathrm{t}=1}^{\tau_{\mathrm{i}}}\left(\overline{\mathrm{X}}_{\mathrm{i}}-\overline{\mathrm{X}}_{\mathrm{G}}\right)^{2}=\sum_{\mathrm{i}=1}^{\mathrm{n}} \sum_{\mathrm{t}=1}^{\tau_{\mathrm{i}}}\left(\mathrm{X}_{\mathrm{it}}-\overline{\mathrm{X}}_{\mathrm{i}}\right)^{2}+\sum_{\mathrm{i}=1}^{\mathrm{n}} \tau_{\mathrm{i}}\left(\overline{\mathrm{X}}_{\mathrm{i}}-\overline{\mathrm{X}}_{\mathrm{G}}\right)^{2} \text {. }
$$

If we mark:

$$
\mathrm{SS}_{\mathrm{W}}=\sum_{\mathrm{i}=1}^{\mathrm{n}} \sum_{\mathrm{t}=1}^{\tau_{\mathrm{i}}}\left(\mathrm{X}_{\mathrm{it}}-\overline{\mathrm{X}}_{\mathrm{i}}\right)^{2} \quad \text { şi } \quad \mathrm{SS}_{\mathrm{B}}=\sum_{\mathrm{i}=1}^{\mathrm{n}} \tau_{\mathrm{i}}\left(\overline{\mathrm{X}}_{\mathrm{i}}-\overline{\mathrm{X}}_{\mathrm{G}}\right)^{2}
$$

we obtain the following equation of the decomposition of the total sum of squares of the deviations:

$$
\mathrm{SA}_{\mathrm{T}}=\mathrm{SS}_{\mathrm{W}}+\mathrm{SS}_{\mathrm{B}},
$$

where: $\mathrm{SS}_{\mathrm{W}}$ (estimator) is called the sum of the squared deviations within groups, and $\mathrm{SS}_{\mathrm{B}}$ (estimator) is called the sum of the squared deviations between groups and it measures inter-group variance.

Consequently, one can say that the $\mathrm{H}_{0}$ referring to mean of the $n$ normal distributions, $\mathrm{H}_{0}: \mu_{1=} \mu_{2}=\ldots=\mu_{\mathrm{n}}=\mu$, can be tested using the following test:

$$
\mathrm{F}=\frac{\frac{1}{\mathrm{n}-1} \mathrm{SS}_{\mathrm{B}}}{\frac{1}{\mathrm{~T}-\mathrm{n}} \mathrm{SS}_{\mathrm{W}}},
$$

where the critical area is determined by the condition $\mathrm{F} \geq \mathrm{F}_{\alpha ; \mathrm{n}-1 ; \mathrm{T}-\mathrm{n} \text {. }}$

For a given significance threshold $\alpha$, the rule for accepting or rejecting $\mathrm{H} 0$ is the following: if the calculated value of $F$ test is higher than $F_{\alpha ; n-1 ; T-n}$, i.e. $F \geq F_{\alpha ; n-1 ; T-n}$,

DOI: $10.24818 / 18423264 / 55.1 .21 .10$ 


\section{Cristina State, Dan Popescu, Minodora Ursăcescu}

$\mathrm{H}_{0}$ is rejected because it is considered that the analysed factor has a significant influence on the response variable. Conversely, $\mathrm{H}_{0}$ is accepted, since it is considered that the analysed factor is non-essential, having an insignificant influence on the response variable.

\section{Research methodology}

The questionnaire was distributed exclusively online so as to offer the respondents the possibility to express themselves freely, without the feeling of being constrained to answer in a pre-established way. We have thus eliminated from the start the "interview effect" and created the premises that the respondents would concentrate on the answers under the protection of anonymity.

The results were processed using the following data analysis techniques:

a) examining the frequency of the responses given to the questions addressed to the study participants;

b) the mean comparison method, analysis of variance (ANOVA) and the linearity test;

c) factor analysis;

d) categorical principal components analysis (CATPCA).

Table 1 renders in a synthetic manner the content elements, as well as the stages of our research methodology. The study was carried out between 28 November 2019 and 26 April 2020.

Table 1: Elements and stages of the research methodology

\begin{tabular}{|l|l|}
\hline Research type & Quantitative \\
\hline Research method & Survey \\
\hline Primary data collection tool & Online questionnaire \\
\hline Measuring tool & Nominal and ordinal measuring scales. Likert scale. \\
\hline Sampling method & $\begin{array}{l}\text { Combination between the quota sampling and snowball } \\
\text { methods, adequate for the exploratory character of the study }\end{array}$ \\
\hline Valid sample volume & 1063 people \\
\hline Target group & $\begin{array}{l}\text { University students and graduates from four university centres } \\
\text { in Romania (Bucharest, Cluj-Napoca, Iaşi and Timişoara) }\end{array}$ \\
\hline Place & Romania \\
\hline Analysis procedure & $\begin{array}{l}\text { Descriptive statistics - analysis: frequency of responses; } \\
\text { response preferences; factor analysis }\end{array}$ \\
\hline $\begin{array}{l}\text { Period and data collection } \\
\text { method }\end{array}$ & $\begin{array}{l}\text { 28.11.2019 - 26.04.2020. Questionnaire published online at } \\
\text { http://isondaje.ro/sondaj/748451261/ }\end{array}$ \\
\hline Data processing & IBM SPSS application \\
\hline & Source: Synthesis by the authors
\end{tabular}

\section{Results and discussions}

The 20 questions included in the questionnaire were structured into separate chapters, so as to reflect as accurately as possible the values referring to how the individuals relate to work. Two of the 1065 people who accessed the questionnaire were eliminated from the study since their answers were invalid.

The statistical results reflecting the gender, age and level of education of the 1063 participants are illustrated in Table 2. 
Empirical Research Regarding the Heavy Work Investment and Workaholism of University Students and Graduates

Table 2: Statistics
\begin{tabular}{|c|c|c|c|c|}
\hline \multicolumn{2}{|c|}{} & Respondents' gender & Age & Education level \\
\hline \multirow{2}{*}{$\mathrm{N}$} & Valid & 1063 & 1063 & 1063 \\
\cline { 2 - 6 } & Missing & 0 & 0 & 0 \\
\hline \multicolumn{2}{|c|}{ Mean } & 1.27 & 2.74 & 5.72 \\
\hline \multicolumn{2}{|c|}{ Sum } & 1353 & 2910 & 6079 \\
\hline \multirow{3}{*}{ Percentiles } & 25 & 1.00 & 2.00 & 5.00 \\
\cline { 2 - 6 } & 50 & 1.00 & 3.00 & 6.00 \\
\cline { 2 - 6 } & 75 & 2.00 & 3.00 & 6.00 \\
\hline
\end{tabular}

Source: Data processed in SPSS by the authors

The demographic structure of the sample, as reflected in Table 3, includes 773 females and 290 males, with ages between 15 and over 50 y.o.

Table 3: Respondents' age

\begin{tabular}{|l|l|c|c|c|c|}
\hline \multicolumn{2}{|c|}{} & Frequency & Percent & Valid Percent & Cumulative Percent \\
\hline \multirow{4}{*}{ Valid } & Female & 773 & 72.7 & 72.7 & 72.7 \\
\cline { 2 - 6 } & Male & 290 & 27.3 & 27.3 & 100.0 \\
\cline { 2 - 6 } & Total & 1063 & 100.0 & 100.0 & \\
\hline
\end{tabular}

Source: Data processed in SPSS by the authors

The results obtained by processing demographic data reflect the characteristics of the quota sampling method, as well as one of its weaknesses: the sampling error cannot be measured or controlled, so that the chosen subjects are grouped in a non-uniform manner by age group, gender or education level (Şandor, 2012).

As indicated in Table 4, the representative segment is made up by the age groups between 23 and 27 y.o. (757 people, accounting for $27.8 \%$ of the total number of respondents) and between 19 and 22 y.o (295 people, or $27.8 \%$ of the total). Overall, of the 1063 respondents 1057 (99.44\% of the total) are aged between 19 and 35 y.o.

Table 4: Respondent's age groups

\begin{tabular}{|c|c|c|c|c|c|}
\hline \multicolumn{2}{|c|}{} & Frequency & Percent & Valid Percent & Cumulative Percent \\
\hline \multirow{5}{*}{ Valid } & $15-18$ years & 1 & .1 & .1 & .1 \\
\cline { 2 - 6 } & $19-22$ years & 295 & 27.8 & 27.8 & 27.8 \\
\cline { 2 - 6 } & $23-27$ years & 757 & 71.2 & 71.2 & 99.1 \\
\cline { 2 - 6 } & $28-35$ years & 5 & .5 & .5 & 99.5 \\
\cline { 2 - 6 } & $36-45$ years & 3 & .3 & .3 & 99.8 \\
\cline { 2 - 6 } & $46-50$ years & 1 & .1 & .1 & 99.9 \\
\cline { 2 - 6 } & $>50$ years & 1 & .1 & .1 & 100.0 \\
\cline { 2 - 6 } & Total & 1063 & 100.0 & 100.0 & \\
\hline
\end{tabular}

Source: Data processed in SPSS by the authors

From the professional view point, the sample corresponds to the criteria imposed to the target group of our study: the respondents have university education, as follows: $295(27.7 \%$ of the total $)$ are undergraduate students or have a bachelor degree; 763 (71.6\% of the total) are enrolled in or have graduated a master course: 5 (0.5\% of the total) are enrolled in or have graduated a doctoral course.

The sample members are highly skilled as far as communication in a foreign language is concerned. Most of them master at least one internationally spoken language (769

DOI: 10.24818/18423264/55.1.21.10 
people, i.e. $72.3 \%$ of the total respondents), while 289 of the study participants (27.6\%) are able to communicate in two or three foreign languages. Only 4 people $(0.1 \%$ of the total) do not know any internationally spoken language.

\section{Testing the research hypotheses}

In order to test the main hypothesis, according to which the $H W I$ of university students and graduates leads to an addiction to work which negatively influences the quality of their professional and personal life in a significant manner, two questions were formulated with the intention of ranking the response options according to their importance. This ranking also allowed us to establish the respondents' personal system of values. The two questions were accessed by all the study participants (Table 5). We used exploratory factor analysis - principal components analysis (Hatos, 2010), completed with factor accuracy analysis which measures the way in which HWI influences the respondents' life. Principal component analysis focuses on the algebraic decomposition of the matrix of the data obtained from the questionnaire into a structure of components called factors, which accumulate a high degree of common variance (Popa, 2008).

Exploratory factor analysis allowed us to identify those variables which explain the model of the variations in a set of 10 variables observed. The algorithm used led to a reduction of the data, so that we were able to identify a small number of factors which explain most of the observed variation, out of a much bigger number of existing variables. The mean score of the registered answers offered a first indication as to how the respondents relate to work. We focused on two different opinions according to which, on the one hand, the people who invest heavily in work, thus becoming workaholic, ,are feeding their adrenaline so that they can work harder and more" (mean score $=3.90$ ). On the other hand, HWI is considered an absolutely normal phenomenon (mean score $=3.89$ ).

Table 5: Descriptive statistics

\begin{tabular}{|c|c|c|c|}
\hline In my opinion, heavy work investment... & Mean & $\begin{array}{c}\text { Std. } \\
\text { Deviation }\end{array}$ & $\begin{array}{c}\text { Analysis } \\
\text { N }\end{array}$ \\
\hline Is motivated by the public recognition of our success & 3.44 & .920 & 1063 \\
\hline Is generated by the need of adrenaline by working as hard as possible & 3.90 & 1.763 & 1063 \\
\hline Is a guarantee that our colleagues will acknowledge our merits & 2.56 & .909 & 1063 \\
\hline $\begin{array}{c}\text { Taken to the point of sacrifice, allows us to obtain the supreme } \\
\text { satisfaction }\end{array}$ & 3.00 & .255 & 1063 \\
\hline $\begin{array}{c}\text { Is beyond any personal success, it makes us feel totally } \\
\text { accomplished, as a result of devoted work }\end{array}$ & 2.10 & 1.775 & 1063 \\
\hline Is a guarantee of career success & 2.09 & 1.758 & 1063 \\
\hline Is not harmful to health if we don't overdo it & 2.56 & .915 & 1063 \\
\hline Can be a positive example for anyone who wants to succeed in life & 3.01 & .225 & 1063 \\
\hline $\begin{array}{c}\text { Can be a real danger, both for us and the organisation we are part of } \\
\text { Is something absolutely normal; I really don't understand why } \\
\text { some people are debating this topic so much }\end{array}$ & 3.45 & .938 & 1063 \\
\hline Source: data process in SPSS by the auth & 1.769 & 1063 \\
\hline
\end{tabular}

Source: data processed in SPSS by the authors 


\section{Empirical Research Regarding the Heavy Work Investment and Workaholism of University Students and Graduates}

Since the answers received did not offer us enough arguments to draw a conclusion on how WI, leading to addiction, can affect the respondents' life, we continued the factor analysis in order to extract the factors which characterize this phenomenon and to nuance the manner in which the analysed factors influence the quality of life. The common variance of the analysed elements is presented in Table 6 . The values the common variance may have fit in the $[0 ; 1]$ interval; the values closer to 1 suggest that the extracted factors explain more the variance of an individual element.

Table 6: Common variance

\begin{tabular}{|c|c|c|}
\hline In my opinion, heavy work investment... & Initial & Extraction \\
\hline Is motivated by the public recognition of our success & 1.000 & .954 \\
\hline Is generated by the need of adrenaline by working as hard as possible & 1.000 & .985 \\
\hline Is a guarantee that our colleagues will acknowledge our merits & 1.000 & .941 \\
\hline Taken to the point of sacrifice, allows us to obtain the supreme satisfaction & 1.000 & .994 \\
\hline $\begin{array}{c}\text { Is beyond any personal success, it makes us feel totally accomplished, } \\
\text { as a result of devoted work }\end{array}$ & 1.000 & .973 \\
\hline Is a guarantee of career success & 1.000 & .978 \\
\hline Is not harmful to health if we don't overdo it & 1.000 & .938 \\
\hline Can be a positive example for anyone who wants to succeed in life & 1.000 & .999 \\
\hline Can be a real danger, both for us and the organisation we are part of & 1.000 & .931 \\
\hline $\begin{array}{c}\text { Is something absolutely normal; I really don't understand why some } \\
\text { people are debating this topic so much }\end{array}$ & 1.000 & .981 \\
\hline
\end{tabular}

Extraction Method: $P C A$

Source: data processed in SPSS by the authors

Most important for the analysis are the results in Table 7 (Total variance explained), which presents a synthesis of the following elements:

a. Component - The initial number of factors, identical with that of the items used in the analysis;

b. Initial Eigenvalues - own values of the factors variance. The factor analysis is carried out in the correlation matrix, where the variables are standardised. Each variable has the initial variance 1 , and the total variance is equal to the number of variables used in the analysis;

c. Total (eigenvalues). The first factor has the highest variance and the biggest eigenvalue, while the successive factors have progressively lower values;

d. Extraction Sums of Squared Loadings - corresponds to the number of extracted factors.

The total variance highlights three factors which cumulated explain $96.73 \%$ of the variance of each element (the eigenvalues are above 1).

The first extracted factor explains $75.79 \%$ of the variance of the 10 elements (Hatos, 2010).

At the same time, the data in Table 8 have facilitated the extraction of the main components by the eigenvalues higher than 1 criterion. This criterion is met by the first three elements.

DOI: $10.24818 / 18423264 / 55.1 .21 .10$ 
Cristina State, Dan Popescu, Minodora Ursăcescu

Table 7: Total variance explained

\begin{tabular}{|c|c|c|c|c|c|c|}
\hline \multirow{3}{*}{ Component } & \multicolumn{3}{|c|}{ Initial Eigenvalues } & \multicolumn{3}{c|}{$\begin{array}{c}\text { Extraction Sums of Squared } \\
\text { Loadings }\end{array}$} \\
\cline { 2 - 7 } & Total & $\begin{array}{c}\text { \% of } \\
\text { Variance }\end{array}$ & $\begin{array}{c}\text { Cumulative } \\
\%\end{array}$ & Total & $\begin{array}{c}\% \text { of } \\
\text { Variance }\end{array}$ & $\begin{array}{c}\text { Cumulative } \\
\%\end{array}$ \\
\hline 1 & 7.580 & 75.799 & 75.799 & 7.580 & 75.799 & 75.799 \\
\hline 2 & 1.075 & 10.746 & 86.546 & 1.075 & 10.746 & 86.546 \\
\hline 3 & 1.019 & 10.185 & 96.731 & 1.019 & 10.185 & 96.731 \\
\hline 4 & .114 & 1.141 & 97.871 & & & \\
\hline 5 & .084 & .836 & 98.707 & & & \\
\hline 6 & .069 & .689 & 99.396 & & & \\
\hline 7 & .044 & .440 & 99.837 & & & \\
\hline 8 & .016 & .163 & 100.000 & & & \\
\hline 9 & $6.007 \mathrm{E}-015$ & $6.007 \mathrm{E}-014$ & 100.000 & & & \\
\hline 10 & $-2.024 \mathrm{E}-015$ & $-2.024 \mathrm{E}-014$ & 100.000 & & & \\
\hline
\end{tabular}

Extraction Method: PCA

Source: data processed in SPSS by the authors

The elements with the biggest weight in the analysis of the relation that establishes the manner in which $H W I$ has a negative impact on the quality of life can be seen in Table 8.

Table 8: Component matrix ${ }^{\mathrm{a}}$

\begin{tabular}{|c|c|c|c|}
\hline \multirow{2}{*}{ In my opinion, heavy work investment... } & \multicolumn{3}{|c|}{ Component } \\
\hline & 1 & 2 & 3 \\
\hline Satisfies our need for adrenaline... & -.991 & & \\
\hline $\begin{array}{c}\text { Is something absolutely normal; I don't understand the people who are } \\
\text { debating this topic so much }\end{array}$ & -.989 & & \\
\hline Is the guarantee of career success & .988 & & \\
\hline $\begin{array}{l}\text { Is beyond any personal/family success, it makes us feel totally } \\
\text { accomplished, as a result of devoted work, meaningful and charming }\end{array}$ & .985 & & \\
\hline Is a guarantee that our colleagues will acknowledge our merits & .967 & & \\
\hline Is not harmful to health, if we don't overdo it & .967 & & \\
\hline Is motivated by the public recognition of our success & -.962 & & \\
\hline Can be a real danger, both for us and for the company & -.937 & & \\
\hline Taken to the point of sacrifice, allows us to obtain the supreme satisfaction & & .994 & \\
\hline Can be a positive example for anyone who wants to succeed in life & & & .993 \\
\hline
\end{tabular}

Extraction Method: Principal Component Analysis. a. 3 components extracted

Source: data processed by the authors using SPSS

The first extracted factor explains $75.79 \%$ of the total variance, indicating the existential addiction to work as a guarantee for career success, but it has the lowest saturation (0.988) of all the extracted factors. The second extracted factor explains only $10.75 \%$ of the total variance, but it has the highest saturation (0.994). This factor characterises the person who invests heavily in work as someone ready to sacrifice his/her existence in order to obtain the supreme satisfaction out of the result of his/ her work. The third extracted factor explains $10.19 \%$ of the total variance and 


\section{Empirical Research Regarding the Heavy Work Investment and Workaholism of University Students and Graduates}

characterises the HWI phenomenon as a positive example for those who want to succeed in life, having a saturation of 0.993.

The internal consistency of the scale measuring the way in which HWI influences the respondents' life is highlighted by analysing the accuracy of the factors which define $W$. This type of analysis is important because in the proposed model we used the factors as independent variables (Popa, 2014). As an indicator we used Cronbachalfa $(\alpha)$ :

$$
\alpha=\frac{N * r m}{1+(N-1) * r m}
$$

where: $N=$ number of items;

$r m=$ mean of the inter-item correlation coefficients

The bidimensional model summary in Table 9 indicated a very high internal consistency $(\alpha=0.968)$. The first dimension was covered in a proportion of $77.83 \%$ by the 10 variables defining the way in which HWI influences the respondents' life, while the second was only $15.14 \%$ covered, the variables having a very low internal consistency ( $\alpha=0.377$ ), although the eigenvalue is supraunitary.

Table 9. Model Summary

\begin{tabular}{|c|r|r|r|}
\hline \multirow{2}{*}{ Dimension } & $\begin{array}{c}\text { Cronbach's Alpha } \\
(\alpha)\end{array}$ & \multicolumn{2}{|c|}{ Variance Accounted For } \\
\cline { 3 - 4 } & .968 & Total (Eigenvalue) & \% of Variance \\
\hline 1 & .377 & 7.783 & 77.830 \\
\hline 2 & $.992^{\mathrm{a}}$ & 1.514 & 15.139 \\
\hline Total & .9 .297 & 92.969 \\
\hline
\end{tabular}

a. Total Cronbach's Alpha is based on the total Eigenvalue.

Source: data processing in SPSS by the authors

The results of the analysis have led us to the conclusion that the $M H$ (the undergraduates' and graduates' $H W I$ leading to $W$ influences their professional and personal life in a negative manner) is confirmed.

The component with the highest factor saturation is represented by the category of respondents who consider that workaholics are people who are ready to sacrifice their existence in order to obtain the supreme satisfaction from their activity (saturation = 0.994), but the answer is not nuanced as to how far they are willing to go in sacrificing their personal life in favour of professional results.

The respondents rank $H W I$ in the hierarchy of personal values as a guarantee for career success, without quantifying however the extent to which this is a positive phenomenon (factor saturation $=0.988$ ). Workaholics are perceived by the respondents as ignoring any personal and/or family achievements in order to feel fully accomplished as a result of the devoted work performed, which is constantly full of meaning and charming. These people work in order to make sure that their merits will be recognised more than those of their colleagues, the conclusion being that HWI is not harmful to health, especially when we know don't overdo it. Last but not least, there is a category of respondents who perceive the HWI phenomenon as a positive example for the people who want to succeed in life.

In order to nuance the fact that the HWI phenomenon leads to the university students'

DOI: $10.24818 / 18423264 / 55.1 .21 .10$ 


\section{Cristina State, Dan Popescu, Minodora Ursăcescu}

and graduates' $W$, which prematurely wears them out and impacts the quality of their professional and personal life in a negative way, we will continue the study with new elements capable to provide punctual answers to new questions by testing the secondary research hypotheses.

a. In order to test $\boldsymbol{S H} \boldsymbol{1}$ we processed the responses received to the following questions:

(6) „When I was a child, my parents and/or grandparents would tell me almost every day...", with response variants from (a) to (g);

(7) In my opinion, considering what I have learned both from my parents and/or grandparents and from school, in order to succeed in life, you should..., with response variants from (a) to (g). The answers received to these two questions were assimilated to a Likert scale from 1 ("the most important") to 7 ("the least important") - (Likert, 1932).

To test this hypothesis we used the mean comparison method, the ANOVA technique and the linearity test, by grouping the data by the "age" variable. The mean values by age groups and for the scale total are situated in the upper part of the Likert scale for 9 of the 12 studied variables. This highlights the influence exerted by the family on the respondents as far as their attitude and, finally, addiction to work are concerned. Depending on the response preference, the respondents believe that in order to succeed in life you should: (1) "work as much as possible, even 14-16 hours per day" (mean score $=6.16$ ); (2) "invest in work, this being a necessity, a pleasure and the guarantee of success" (mean score = 4.89); (3) "fact in such a way as to bring the highest possible income to the organisation you are part of, irrespective of whether it is your own business or it belongs to someone else" (mean score = 4.45); (4) "you shouldn't trust others; people are very mean and very sly?" (mean score = 3.91); (5) "you shouldn't stress out too much because society will progress anyway, even without your contribution" (mean score = 3.57); (6) "you you should do what we tell you is best for you! Because we mean well! (mean score = 3.45); (7) "When you do something, do it well! Don't be concerned about the others!" (mean score = 3.01); (8) "If you want to succeed, you must work hard!" (mean score = 2.55). In this first stage, ranking the answers according to the mean score shed light on the role the family plays in shaping the people's views regarding the importance and usefulness of work investment and $W$, as well as the manner in which the respondents relate to work. The ANOVA variance test confirmed the fact that the differences in the response preferences are significant, with a well-defined hierarchy of the opinions ( $\mathrm{Sig}=$ 0.000). The respondents' age has an important influence when it comes to refining the response preferences for each question (between 80-90\%). The exception is represented by the variant "When you do something, do it well!", where the respondents' age had a much smaller influence on the response preferences $(12.6 \%)$. To conclude, considering the arguments above, SH1 is confirmed, since the undergraduates' and graduates' inclination towards HWI is, indeed, induced since childhood, by means of the education received from the family.

b. applying the same work algorithm, we tested $\boldsymbol{S H} \mathbf{2}$ by analysing the answers to question (12): "I believe that people work as much as possible because (1 - the most 


\section{Empirical Research Regarding the Heavy Work Investment and Workaholism of University Students and Graduates}

important, in my opinion; ... 5 - the least important, in my opinion). The mean scores are situated in the upper part of the 5-point Likert scale for three of the proposed response options, as follows: (1) "for the organisation they are part of" (mean = 3.98); (2) "To generate the pleasure of working for the benefit of their community and country of origin" (mean = 3.94); (3) "for one's own merits to be acknowledged at social level" (mean $=3.00$ ). In this case too, the ANOVA test confirmed that the differences in the response preferences of the study participants are significant and that there is a clear ranking of the response options ( $\mathrm{Sig}=0.000)$. The respondents' age had an important influence (between 50 and 90\%) in refining the response preferences for this question. Based on these arguments, SH2 is also confirmed, HWI being also a result of the influences exerted by the environment (such as the fear of feeling embarrassed in front of the others);

c. SH3 was tested using the same work algorithm, by analysing the answers to question (13): "Which of the following statements do you think characterises you to a great extent?" (1 - the most important, in my opinion; ... 10 - the least important, in my opinion). The mean scores are situated in the upper part of the 10 - point Likert scale for six of the proposed response options, indicating the respondents' strong convictions. The ranking of the registered answers highlights the most frequent problems the respondents are confronted with, such as: (1) "I often have pains in my chest and I suffocate (mean =7.57); (2) "More and more I have nightmares caused by stress and/or insomnia" (mean = 7.07); "When I come from my workplace I usually work on until late at night, especially that it is so quiet" (mean =6.62); (3) "I don't remember when I had my last medical leave" (mean = 6.17); (4) "I am more and more anxious, impatient, I lose control and I burst out" (mean = 5.74); (5) "It is happening more and more often that I feel awkward, I judge myself very harshly, as I consider I can't handle things well enough" (mean 5.30). The ANOVA variance test confirmed that the differences in the response preferences of the study participants are significant and that there is a clear ranking of the response options $(\mathrm{Sig}=0.000)$. The respondents' age also had an important influence in refining the response preferences for each of the questions (between 33 and 95\%). The arguments presented allow us to state that SH3 is also confirmed, i.e. indeed, HWI has deeply negative effects on the people's psychological health;

d. another aspect tackled in our study was verifying the principle according to which educated people's need that their place, role and social usefulness should be acknowledged leads, in time, through heavy work investment, to $W$. In order to verify SH4 we used the optimal scaling technique - the categorical principal components analysis $(C A T P C A)$. The procedure simultaneously quantifies the categorical variables and reduces the data dimensionality, allowing for the interpretation of some no correlated variables which represent most of the identified information in the original variables, instead of a big number of variables. The method consisted in extracting some latent factors, common to a set of variables and in identifying the way in which the variables can explain the latent factor. The criterion used by CATPCA is that of the big correlations that should exist between the scores of the components and each of the

DOI: $10.24818 / 18423264 / 55.1 .21 .10$ 
quantified variables. The solution which meets this criterion is considered to be "good" (Meulman and Heiser, 2001). The variables selected to describe the effects of $H W I$ leading to $W$ were analysed in close connection with the respondents' proven education level, through the answers given the last question (20): "Finally, I believe that heavy work investment is ( 1 - the most important, in my opinion; ... 5 -the least important in my opinion): (1) "something "poetic", but urging you to be a better, more efficient person"; (2) "a necessary evil"; (3) "a matter of principle for a person who was educated to be useful to society"; (4) "an attitude when confronted with unpredictable, bad situations"; (5) "something dangerous, which can trigger strong psychological and emotional imbalances and not only". The summary of the bidimensional model indicated that the first dimension is covered by the five variables selected to define $W$ in a proportion of $81.32 \%$, and that the internal consistency is very good - Cronbach Alpha $=0.954$. The second dimension is covered in a proportion of $16.79 \%$ the internal consistency of the variables being insignificant - Cronbach Alpha $=0.009$, in spite of the fact that the eigenvalue is supraunitary (1.007). The values obtained prompted us to reject the existence of the second dimension and to retain only the factors which have, concomitantly, a good internal consistency and a supraunitary eigenvalue. (Meulman şi Heiser, 2001). The cloud of plots associated to the two extracted dimensions concentrates around the vertical axis. A series of respondents are very well represented in the first dimension (Figure 1) and very weakly or not at all in the second (Figure 2).

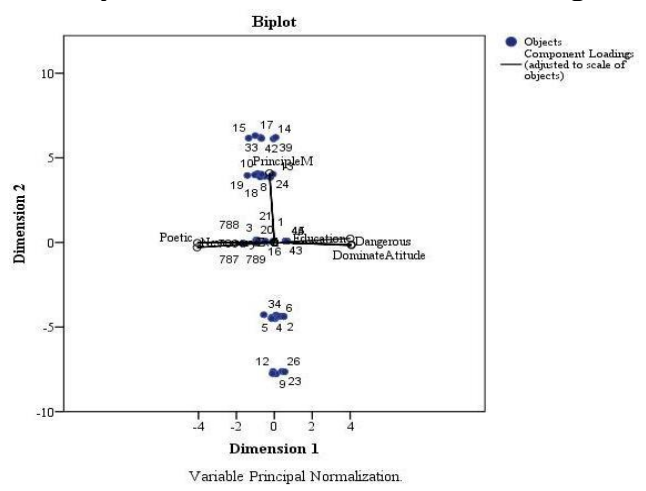

Figure 1: Plot cluster of scores associated to the two extracted dimensions

Source: Data processed in SPSS by the authors

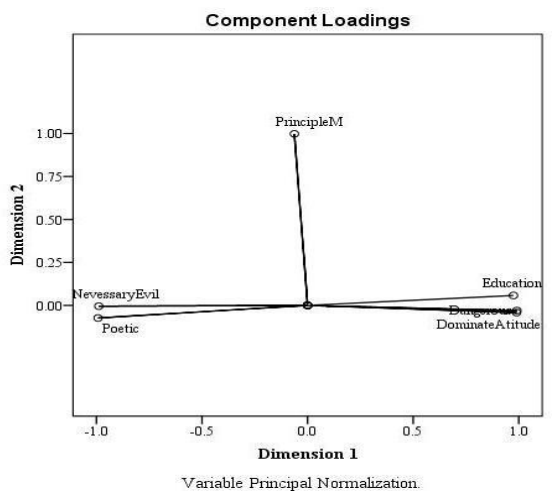

Figure 2: Coordinates of factor saturation

The graphic representation of the coordinates of the studied variables which define the relation between $H W I$ and $W$ and the need of educated people that their social usefulness should be acknowledged, the correlations between the variables and the way in which the variables relate to each of the two dimensions can be seen in Figure 1. Three of the variables show a positive value of the factor saturation for the first dimension, which means that no common factor correlates positively with all the variables. (Meulman şi Heiser, 2001). The graphic position of the vectors forms two distinct groups, which differentiate the values established between the variables. So, 


\section{Empirical Research Regarding the Heavy Work Investment and Workaholism of University Students and Graduates}

the first group is made up of two positively associated variables which define $H W I$ and which are strongly correlated both with each other and with the respondents' level of education. The respondents included in this group consider that " $H W I$ leading to $W$ " is "a dangerous phenomenon, which can trigger strong psychological and emotional imbalances", but also "an attitude when confronted with unpredictable situations, with the "evil" which is trying to get hold of each of us in a society that is increasingly devoid of the authentic values of work and welfare". The second group contains two negatively associated variables represented by the respondents who believe that $H W I$ leading to $W$ "is a necessary evil" or "something "poetic", but urging you to be a better person, more efficient and better integrated in the existing organisational structures". A separate vector is represented by the respondents who consider that $H W I$ leading to $W$ is "a matter of principle for an educated person to be useful to society".

The size of the analysed phenomenon (HWI leading to W generated by the need of an educated person that their social usefulness should be acknowledged) is nuanced by the degree of association of the variables. The registered responses are placed in two categories of associated variables and an orthogonal, independent variable $(O I V)$. In this context, according to CATPCA, the degree of association of the variables is given by the way in which the vectors defining each variable are grouped. In the case of $\boldsymbol{S H 4}$, the angle between the vectors is of 180 degrees (Figure 1), which means that the variables are not associated (Linting et al., 2007). OIV is represented by the respondents who believe that WI and W are a matter of principle for an educated person to be useful to society and they are not associated to any of the other variables (Linting et al., 2007, p.351). The existence of OIV (lack of association with the other studied variables) determined us to reject the SH4. In other words, it is not confirmed that the people's HWI is also stimulated by their need, as educated people, to have their place, role and usefulness in society acknowledged by the others.

\section{Conclusions}

The research has highlighted several dysfunctionalities generated by $H W I$, in the sense of people becoming addicted to work. New aspects related to the effects of $H W I$ have been revealed, which can represent the starting point for new research studies dedicated to this phenomenon.

The results obtained have confirmed that the undergraduates' and graduates' $H W I$ has a decisive, negative impact on the quality of their professional and personal life. Practically, the usefulness or lack of usefulness of $H W I$ to university students and graduates is a topic which raises new question marks, as well as well as it incites to further research. In this sense, the results of the study have demonstrated that the university students' and graduates' $H W I$ is instilled into them ever since childhood, through the education they receive from their family. On the other hand, another conclusion comes from the confirmation of the fact that the university students' and graduates' $H W I$ is generated by the influences exerted by the environment (such as

DOI: $10.24818 / 18423264 / 55.1 .21 .10$ 
Cristina State, Dan Popescu, Minodora Ursăcescu

the fear of feeling embarrassed in front of the others). We have also demonstrated that in the study participants' opinion, $H W I$ has highly negative effects on their psychological health, which is a deeply harmful phenomenon.

The research results have invalidated the fact that university students and graduates invest in work out of their own need, as educated people, who want their role, place, role and social usefulness to be acknowledged by the others.

However, a clear-cut answer to the dilemma of our study is subjective and risky, since it depends on the options and values of each of the respondents and generalising, of each individual. It is obvious that $H W I$ ever since university years has both positive and negative effects (acquisition of new knowledge and skills vs. neglecting one's studies and $W$ ).

A limitation of our research consists in the fact that have not dealt with the deeply negative effects of the pandemic crisis on $W$, especially that it has been proven that man can adapt extremely fast to anything, even to working in other conditions, imposed by working from home, due to digitalisation, which is also a form of $W$. This why we consider that the present results open up new research perspectives, correlated with particular aspects that would pinpoint the extreme situations of the relationship between man and work, starting from being forced to give up one's job and accepting technical unemployment (in the best case scenario), to telework or resuming one's professional activity in completely new conditions, where the term "socialisation" (including socialising in the work place) acquires dimensions and meanings we have never been confronted with.

\section{REFERENCES}

[1] Babic, A., Stinglhamber, F., Barbier, M., Hansez, I. (2019), Work Environment and Work-to-Family Conflict: Examining the Mediating Role of Heavy Work Investment; Journal of Management \& Organization, June, 1-24;

[2] Baert, S. et al. (2017), Student Employment and Academic Performance: An Empirical Exploration of the Primary Orientation Theory; Applied Economics Letters, 25(8), 547-552;

[3] Berman, J. (2018), Students who Hold Jobs during College Earn More Money after they Graduate, Retrieved from: https://www.marketwatch.com/story/ students-who-do-this-during-college-earn-more-money-as-graduates-2018-0102 ;

[4] Cronbach, L.J. (1951); Coefficient Alpha and the Internal Structure of Tests. Psychometrika (16), 3;

[5] Earp, B.D., Skorburg, J.A., Everett, J.C., Savulescu, J. (2019), Addiction, Identity; Morality, AJOB Empirical Bioethics, 10(2), pp.136-153;

[6] Ford, J.H., Conners, S. (2010), Confucius. The Teachings of Confucius. El Paso Norte Press;

DOI: $10.24818 / 18423264 / 55.1 .21 .10$ 
Empirical Research Regarding the Heavy Work Investment and Workaholism of University Students and Graduates

[7] Griffits, M.D., Demetrovics, Z., Atroszko, P.A. (2018), Ten Myths about Work Addiction. Journal of Behavioral Addictions, 7(4), 845-857;

[8] Harpaz, I., Snir, R. (Eds.). (2014,. Heavy Work Investment: Its Nature, Sources, Outcomes, and Future Directions. Routledge/Taylor \& Francis Group;

[9] Hatos, A. (2010), Analiza datelor sociale. Îndrumar de laborator. Retrieved from: https://www.researchgate.net/publication/337242925_analiza_datelor_sociale _indrumar_de_laborator ;

[10] Huyghebaert, T. et al. (2018), Examining the Longitudinal Effects of Workload on Ill-being through each Dimension of Workaholism; International Journal of Stress Management, 25(2), pp.144-162;

[11] Joubert, M. (2020), Social Work students' Perceptions of their Readiness for Practice and to Practise; Social Work Education, 4(May), 1-24;

[12] Kirschner, P., Stoyanov, S. (2020), Educating for Nonexistent/Not Yet Existing Professions; Educational Policy, 34(3), 477-517;

[13] Likert, R. (1932), A Technique for the Measurement of Attitude. Archives of psychology, 140, 21-33. Retrieved from: https://www.legacy.voteview.com/pdf /Likert_1932.pdf;

[14] Linting, M., Meulman, J., Groenen, P., Van der Kooj, A. (2007), Nonlinear Principal Components Analysis: Introduction and Application. Psychological methods, 12(3), 336;

[15] Listau, K., Christensen, M., Innstrand, S. (2017), Work Engagement: A Double -edged Sword? A Study of the Relationship between Work Engagement and the Work-Home Interaction Using the ARK Research Platform; Scandinavian Journal of Work and Organizational Psychology, 2(1), 1-13;

[16] Meulman, J., Heiser, W. (2001), SPSS Categories 11.0. Chicago: SPSS;

[17] Moss, J. (2019), When Passion Leads to Bornout; Harvard Business Review, [online]. Retrieved from: https://hbr.org/2019/07/when-passion-leads-to-burnout;

[18] Oates, W. (1971), Confessions of a Workaholic: The Facts about Work Addiction. New York: World Publishing Co.;

[19] Opariuc-Dan, C. (2011), Statistică aplicată în şstiinţele socio-umane. Analiza asocierilor şi a diferenţelor statistice. Sibiu: Arhip-Art;

[20] Ostertagova, E., Ostertag, O. (2013), Methodology and Application of Oneway ANOVA; American Journal of Mechanical Engineering, 1(7), 1-21;

[21] Park, S., Martina, R., Smolka, K. (2019), Working Passionately Does Not always Pay off: The Negative Moderating Role of Passion on the Relationship between Deliberate Practice and Venture Performance; The Anatomy of Entrepreneurial Decisions, Springer, 173-195;

[22] Peart, N. (2019), The 12 Most Important Skills You Need To Succeed At Work, Retrieved from: https://www.forbes.com/sites/nataliapeart/2019/09/10/the-12-most -important-skills-you-need-to-succeed-at-work/\#15416ce41c6a ;

[23] Popa, M. (2011), Infidelitățile” coeficientului de fidelitate Cronbach alfa. Psihologia resurselor umane, 9(1), 85-99;

DOI: $10.24818 / 18423264 / 55.1 .21 .10$ 
Cristina State, Dan Popescu, Minodora Ursăcescu

[24] Popa, M. (2008), Statistică pentru psihologie: teorie şi aplicaţii SPSS. Iaşi: Polirom;

[25] Ruxanda, Gh. (2010), Analiza multidimensională a datelor; ASE Publishing;

[26] Sanchez-Gelabert, A. Figueroa, A., Elias, M. (2017), Working whilst Studying in Higher Education: The Impact of the Economic Crisis on Academic and Labour Market Success; European Journal of Education, 52(2), 232-245;

[27] Schmall, T. (2019), Almost half of americans consider themselves 'workaholics'; Retrieved from: https://nypost.com/2019/02/01/almost-half-of-americans-considerthemselves-workaholics/;

[28] Scholz-Fenech, C., Raykov, M. (2018), Studying and Working - Hurdle or Springboard? Widening Access to Higher Education for Working Students in Malta, in Curaj, A., Deca, L., Pricopie, R. (2018), European Higher Education Area: The Impact of Past and Future Policies, 237-258, Springer;

[29] Schram, A. (2019), Live to Work or Work to Live: Which Would You Choose? [online], Retrieved from: https://www.maplemoney.com/live-to-work-to-live/;

[30] Smith, M. et al. (2019), Perfectionism and the Five-factor Model of Personality: A Meta-analytic Review; Personality and Social Psychology Review, 23(4), 367390;

[31] Șandor, D.S. (2012), Metode și tehnici de cercetare în domeniul științelor sociale. Cluj-Napoca: Babeş-Bolyai University Publishing;

[32] Van Beek, I. et al. (2014), Heavy Work Investment: Its Motivational make-up and Outcomes; Journal of Managerial Psychology, 29(1), 46-62;

[33] Wojdylo,K. (2015) 'Workaholism" Does not always Mean Workaholism? About the Controversial Nomenclature in the Research on Work Addiction; Polish Psychological Bulletin, 46(1), 133-136. 